https://doi.org/10.48009/1_iis_2021_149-163

\title{
Does web camera usage in synchronous lessons affect academic emotions?
}

\author{
Idan Roth, The Academic College of Tel-Aviv-Yaffo,idanro@mta.ac.il \\ Ruti Gafni, The Academic College of Tel-Aviv-Yaffo,rutigafn@mta.ac.il
}

\begin{abstract}
The purpose of this study was to investigate whether students' web camera usage is beneficial to their academic positive emotions and to explore whether the effect of self-efficacy on academic positive emotions, which was previously found within the co-located setting, applies to the new distant learning environment. Data were collected using a survey distributed in synchronous distance-learning classes, of undergraduate students. Confirmatory factor analysis was performed to assess data model fit and model adjustment, and to investigate the causal relations among latent and observed variables in this a-priori specified, theory-derived model. The associations between self-efficacy and positive emotions and between the use of web cameras and positive emotions were investigated using multiple regression models. The moderation effect of self-efficacy on the association between the use of a web camera and positive emotions was tested using Hayes' Process Macro. The findings indicated that even when using synchronous distance learning, self-efficacy positively affects positive emotions. Moreover, students characterized with low levels of self-efficacy will benefit from the use of a web camera in synchronous distance learning and will experience higher levels of positive emotions. Due to COVID-19 constraints, online learning is no longer an option, but rather the only option, for synchronous courses. This requires investigating and reaffirming the effects that were previously found in co-located courses, gaining a more in-depth understanding of the importance of web camera usage in this isolated setting.
\end{abstract}

Keywords: self-efficacy, positive emotions, CMC richness, web camera, COVID-19, synchronous distance learning, online learning

\section{Introduction}

The outbreak of COVID-19 necessitated rapid adjustments worldwide, prompting colleges and universities to move all in-person, face-to-face courses to a remote or online learning (Lowenthal et al., 2020). The authors' college faculty, together with college IT department quickly dealt with the technological challenges, and for over a year now, all courses have been managed via distance learning synchronous tools, especially Zoom. Zoom facilitates a videoconference setting, in which each student and teacher can be in another place physically, but still participate in the same online lesson. The students can participate with either an open or closed web camera; however, college teachers encourage students to turn on their web cameras, to create the feeling of a face-to-face class. Nevertheless, the majority of students prefer not to turn on their web cameras. When requested specifically to do so by the teachers, cooperation is only marginal. This phenomenon has several negative results, as has been previously reported by higher education institutes (Al-Jarf, 2020). For example: Teachers often feel that they are "speaking mostly to themselves"; attempts to hold a discussion by raising questions are often unsuccessful, and the questions 


\section{Issues in Information Systems}

Volume 22, Issue 1, pp. 149-163, 2021

remain unanswered; and students' complaints re dissatisfaction with the newly online setting, Hence, this paper investigates the importance of web camera usage during synchronous lessons.

\section{Literature review}

Earlier work of researchers and educational psychologists mainly focused on factors influencing the students' academic success, and consisted of co-located teaching experiences (Mega et al., 2014). However, COVID-19 forced a transition from the co-located learning approach to the remote or distance learning online approach - posing new and significant challenges for both students and teachers. Social distancing, one of the consequences of COVID-19, results in a stronger reliance on self-regulated learning, home facilities, and procrastination (Meeter et al., 2020). An additional distance learning outcome reported by Meeter et al. (2020) was a decrease in hours being spent for study purposes. Hence, an attempt to understand the impact of distance learning on students' academic success requires an investigation of the origins of academic success.

Emotions and Self-Efficacy - Emotions are argued to affect learning performance (Goleman, 1995; JohnSteiner, 2000; Piaget, 1989; Vygotsky et al., 1994); and similarly, positive emotions affect the performance of cognitive activities (Izard, 1985). Emotions are reactions to important events and states, and academic emotions are emotions that relate to learning, instruction, and achievement in academic settings (Pekrun et al., 2002). Thus, academic emotions are a salient building block of academic success, and previously defined as "those which are directly related to achievements, activities, and outcomes" (Pekrun, 2006). An endeavor to create a student's achievement emotions construct yielded a 24-scale instrument, known as the Achievement Emotions Questionnaire (AEQ). This tool assesses various achievement emotions experienced by students in academic settings (Pekrun et al., 2011). The instrument includes nine different emotions, and measures both positive and negative emotions, in congruence to activation themes, offering four emotion categories comprising the valence and activation dimensions (Pekrun et al., 2011). The positive activating emotions dimension, composed of enjoyment, hope, and pride, was found to be positively related to most of the measured variables. One of the significant antecedents of academic emotions is cognitive assessment (Pekrun, 2006; Pekrun et al., 2007), whose assessment may be carried out using a Self-Efficacy construct. Self-efficacy is the self-assessment of one's ability to master a task. It includes judgment about one's ability to accomplish a task as well as one's confidence in his or her skills to perform that task (Pintrich et al., 1991). Self-efficacy can predict or cause emotions, where higher levels of self-efficacy relate to higher levels of positive emotions (Burić \& Macuka, 2018). Achievement emotions control-value theory (Frenzel et al., 2009) posits that in an academic context, personal self-efficacy predicts positive emotions. Later empirical studies displayed this effect with teachers (Burić \& Macuka, 2018; Salanova et al., 2010; Taxer \& Frenzel, 2015), where higher levels of teachers' self-efficacy beliefs predicted higher levels of positive emotions (Burić et al., 2020).

Benefits of and barriers to using web cameras in distance learning before COVID-19 - Distance learning is not a new concept, and neither is using videoconference options for synchronous teaching. The use of web cameras helps create a sense of interaction in a distance learning environment is (Anderson et al., 2003), supporting cross-site fluid conversation. Using web cameras for distance learning has both benefits as well as barriers. In order to simulate face-to-face lessons, meaningful teacher-student and student-student interaction is a must (Gruber \& Bauer, 2020). One of the important benefits of using web cameras is increasing this sense of presence. Social presence in online communication can be defined as the degree to which a person is perceived as 'real' (Short et al., 1976). According to the research of Short et al. (1976), social presence contributes to the social aspect of online communication and influences "interaction, motivation, group cohesion, social equality, and in general to the socio-emotional climate of a learning experience". The possibility to see others during a distance learning lesson enables the viewing 


\section{Issues in Information Systems}

Volume 22, Issue 1, pp. 149-163, 2021

of gestures and facial cues, like in a real face-to-face classroom, which creates a higher level of social presence than the use of audio alone (Gunawardena \& McIsaac, 2003). According to Albuquerque and Velho (2003), the students' sense of presence increases when they have the capacity to see the gestures and facial expressions of the other participants. Those who choose to use web cameras seek the reciprocal behavior of the other students. To these students, web camera usage is considered fundamental. Moreover, web cameras strengthen teacher-student relationships (Griffiths \& Graham, 2009). The ability to feel "together" with others, without actually sharing the same physical space, enables the sense of being part of a realistic community, with smooth, natural and engaging communication and collaboration, increasing students' satisfaction (Blas \& Poggi, 2007; McBrien et al., 2009), and elevates their self-confidence levels (Telles, 2010). Moreover, in Telles' research (2010), students reported that in online communication without web cameras the experience seemed artificial, technical, electronic, distant, and impersonal. Teachers benefit from receiving nonverbal cues from their students such as smiles, frowns, head nods, looks of confusion, and looks of boredom, because these cues allow them to evaluate their teaching in real time and adjust accordingly to improve student learning (Miller, 1988; Mottet \& Richmond, 2002). Along with the benefits, prior research also reports of barriers to online learning. Research found technical complications related to web camera usage, such as web cameras and microphones that are "built-in" to laptops, which are often of low quality, have a fixed angle, and sound-introducing echoes (Fita et al., 2016). Another drawback is that participants can observe their partner's surroundings, which provides insight into the other students' lives (Telles, 2010). This can be an obstacle for students from low, socio-economic backgrounds, or those who do not want to share their private environment. Yet another problem is that using a web camera means the students see not only all the other participants, but also themselves, as in a mirror, all the time. This fact has both pros and cons. Yamada and Akahori (2009) found that although seeing one's self-image during a lesson can maintain the student's attention and help them see themselves from the perspective of a third person, many people do not like to see themselves through a mirror all the time and may be embarrassed.

Distance learning and compulsory web camera usage because of the COVID-19 pandemic - Because of the sudden change caused by the pandemic and the need to go online, technological issues -like having a web camera, and knowing how to use it - were, for the most part, rapidly resolved. However, other kinds of barriers still exist, such as low internet bandwidth, which hinders the flow of the video, or the preferences of some individuals to connect visually anonymously. Many teachers now find themselves teaching remotely for the first time and facing new challenges, like not being able to see students during synchronous class meetings held via the internet, because students do not have their web cameras turned on (Castelli \& Sarvary, 2021; Reich et al., 2020). The ability to turn off the web camera in video conference mode; yet still be able to attend and interact during the course with teachers in real time, seems to have a lot of attraction for students (Greener, 2021). Additionally, it was found that students appreciated online education less than they did traditional, face-to-face classes, and said they felt less motivated using the remote learning approach (Meeter et al., 2020). Moreover, online distance classes are more teacher-centered than face-to-face sessions, and group or whole-class discussions are characterized by longer silences and shorter student responses. Having such discussions is even harder when students turn their web cameras off, due to privacy concerns (Moorhouse, 2020). Castelli and Sarvary (2021) reported that, at first, they did not compel students to turn on their web cameras during class, but only encouraged them to do so. However, as the semester progressed, students' decreasing web camera usage affected the educational experience as a whole, and teachers began to feel as if they were "talking to themselves". The most frequent reported reason for turning off one's web camera were being concerned about their environment: (1) other people in the background, or (2) embarrassed of their home environment (Castelli \& Sarvary, 2021; Neuwirth et al., 2020). Another, less frequent reason related to student's behavior: (3) personal appearance and not being properly dressed (pajamas, hair, etc.), (4) not wanting to be seen walking away from the computer, (5) not paying attention or (6) doing other things while at the computer (Castelli \& Sarvary, 2021; Neuwirth et al., 


\section{Issues in Information Systems}

Volume 22, Issue 1, pp. 149-163, 2021

2020). Only a very small number of students reported technical reasons such as (7) malfunctioning web cameras, (8) absence of appropriate personal equipment (web camera, headphones), or (9) having an unstable internet connection and insufficient bandwidth (Krystalli, 2020; Neuwirth et al., 2020).

\section{Research questions and hypotheses}

This research focuses on three aspects of students' attitudes towards the distance learning approach adopted because of the COVID-19 pandemic:

(1) The effect of self-efficacy on positive academic emotions under social distancing conditions Emotions are central to the understanding of students' learning and achievement (Govaerts \& Grégoire, 2008; Pekrun, 2006; Weiner, 2010), and students' self-efficacy has an impact on their learning-related emotions (Hayat et al., 2020). This paper argues that although it is possible to enforce social distancing measures, this is not natural human behavior. Therefore, the impact of self-efficacy on positive academic emotions is expected to continue to be present in distance synchronous learning, just as it is in traditional, face-to-face learning settings. Hence, we propose the following hypothesis:

\section{H1: Greater self-efficacy is associated with higher positive academic emotions.}

(2) The effect of web camera usage on positive academic emotions

A recent work (Castelli \& Sarvary, 2021) reported various factors that deter students from turning on their web cameras when engaging in distance learning. Some factors are environmentally driven; others originate from students' behavior, and a few were technical in nature. None, however, were related to academic emotions. Therefore, we propose the following hypothesis:

\section{H2: Greater web camera usage is not associated with higher levels of positive academic emotions.}

(3) The effect of web camera usage on positive academic emotions with different levels of self-efficacy COVID-19 is characterized by the need for social distancing, which imposes more reliance on self-regulated learning (Meeter et al., 2020). Since face-to-face courses were found to be preferable to online distance learning, and since students with low self-efficacy levels may find self-regulated learning more challenging, students with lower levels of self-efficacy are expected to try to stick with the setting that most closely resembles the face-to-face setting. This option is reflected in the synchronous lesson method, supported by a web camera, which enables teachers to be exposed to students' nonverbal cues (Miller, 1988; Mottet \& Richmond, 2002). This provides teachers with a better understand of students' needs, and allows them to adjust the flow of the lesson in accordance. An improved learning process is expected to affect students' enjoyment, happiness, and sense of pride - or in other words, to increase their positive emotions. Additionally, web camera usage maintains students' attention (Yamada \& Akahori, 2009), which in turn, also improves the learning processing. Therefore:

H3: The positive association between web camera usage and positive academic emotions is greater for low self-efficacy students.

Table 1 lists the constructs used to build the three hypotheses, and Figure 1 shows the relationships between them. 
Table 1. Constructs and corresponding measures

\begin{tabular}{|l|l|}
\hline \multicolumn{1}{|c|}{ Constructs } & \multicolumn{1}{c|}{ Measures } \\
\hline Self-efficacy & $\begin{array}{l}\text { "Beliefs in one's capabilities to organize and execute the courses of action } \\
\text { required to produce given attainments" (Bandura, 1997) }\end{array}$ \\
\hline $\begin{array}{l}\text { Positive academic } \\
\text { emotions }\end{array}$ & $\begin{array}{l}\text { Positive emotions related to learning, instruction, and achievement in academic } \\
\text { settings (Pekrun et al., 2002) }\end{array}$ \\
\hline Web camera usage & The extent of students' use of a web camera during the course \\
\hline
\end{tabular}

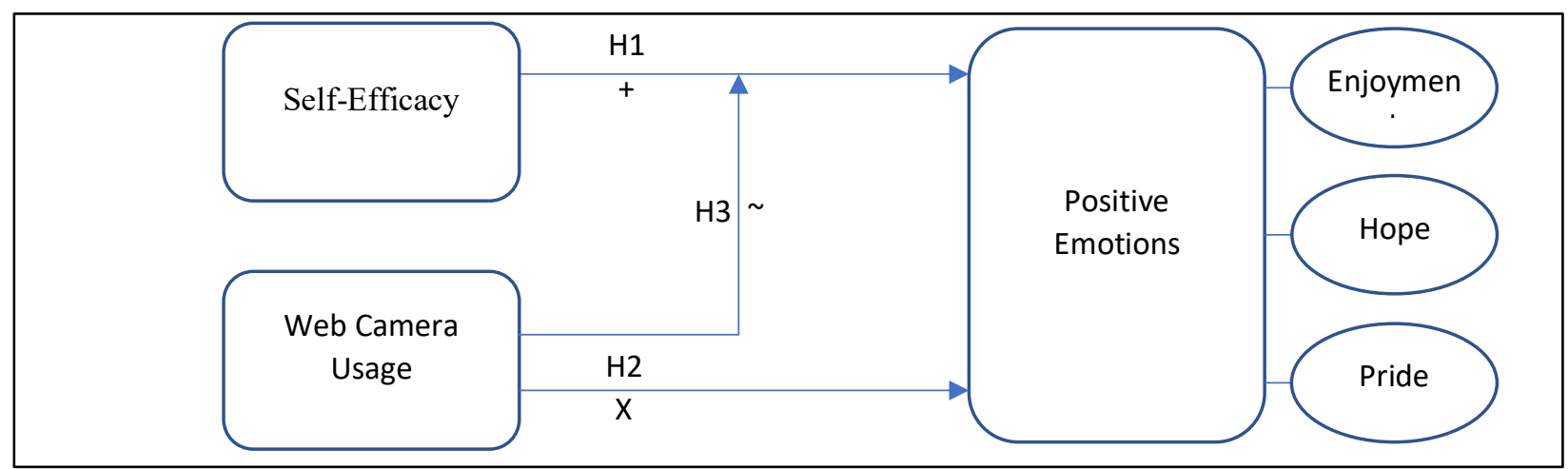

Figure 1. The research model

\section{Methodology}

In order to obtain the data for this research, a questionnaire was prepared, which was composed of several sections, adapted from prior research, as follows:

1. The Self-Efficacy construct was composed of a subset of a Motivated Strategies for Learning Questionnaire (MSLQ) (Pintrich et al., 1991), and consisted of eight items with a 7-point Likert scale ("not at all true" (1) to "completely true" (7)).

2. Positive emotions was one of the classifications of academic emotions results, and included enjoyment, pride, and hope (Pekrun et al., 2002). A later work offered four dimensions of emotions (Pekrun et al., 2011); one of them - the positive activating emotions dimension - was similarly comprised of enjoyment, hope, and pride.

The adapted AEQ (Pekrun et al., 2011) consisted of the original number of items per emotion: ten items for the Learning-Related Enjoyment emotion, six items for the Learning-Related Hope emotion, and six items for the Learning-Related Pride emotion. The 5-point Likert scale ("completely disagree" (1) to "completely agree" (5)), which was used in the original research, was adopted.

3. Finally, the section pertaining to extent of web camera usage consisted of a single question with a 7point Likert scale ("completely disagree" (1) to "completely agree" (7)).

Data was gathered a couple of weeks before the end the semester, on December 30, 2020, via a web questionnaire, using Google Forms. This specific semester was taught entirely via Zoom. The participants were all undergraduate students from two courses in an Information Systems Program. One course was part of the first-year study program, and the second course was part of the second-year study program. Towards the end of the semester, the teachers encouraged their students to participate, voluntarily and anonymously, 


\section{Issues in Information Systems}

Volume 22, Issue 1, pp. 149-163, 2021

in this research. Confidentiality was assured; however, students were asked to provide, if they agreed, their emails and textual comments. Analysis of the internal structure of the scales was executed with IBM SPSS ${ }^{\circledR}$ Amos 22.0.0, using confirmatory factor analysis (CFA). Analysis of the effect of the independent constructs, self-efficacy and web camera usage, on the dependent construct, positive emotions, was executed with the statistical software SPSS 20.0.0, using multiple regressions. The moderation effect was performed using Hayes's Process Macro state-of-the-art statistical methods (Hayes, 2013).

\section{Findings}

The participants were 215 undergraduate students (51.63\% females, 48.37\% males), 121 in their first year and 94 in their second year of academic studies. The rule of thumb for sample size (Hoyle, 1995; Loehlin, 1992) recommends a sample size of at least 100 cases, and preferably 200 . Therefore, this study meets the minimum requirements suggested. The initial statistical run provided acceptable model fit results, with $\mathrm{CFI}=0.836$ and $\mathrm{TLI}=0.821$, though RMSEA values were less desirable (0.089). An observation of the regression weights during the initial statistical run indicated that one of the self-efficacy latent variables was insignificant. Notwithstanding, several pairs of error displayed high modification indices rates. Therefore, the model was updated accordingly, the insignificant self-efficacy item was removed, and a covariance was added to four pairs of errors, each pair within the same factors. Thus, a statistical analysis of the modified model provided improved model fit results, with minimum discrepancy per degrees of freedom $(\mathrm{CMIN} / \mathrm{DF})=2.09$, an acceptable fit value between the hypothetical model and the sample data (Kline, 1998). A good model fit is often characterized by a statistically insignificant Chi-square value. However, this statistic is sensitive to sample size (Schermelleh-Engel et al., 2003; Vandenberg, 2006), and therefore is overlooked in this research. In other CFA results, the model fit indices were also acceptable: with $\mathrm{RMSEA}=0.07$; CFI $=0.90$; and TLI $=0.89$. Although some of the factor loadings (Path estimates) were less than 0.5 , due to the acceptable model fit and the desire to align with previous work, which addressed all items, the decision was not to omit these items, regardless of their low factor loading values (Table 2). Reliability was measured using Composite Reliability (CR) to verify the consistency of latent constructs. The $\mathrm{CR}$ values exceeded the 0.6 cutoff; therefore, reliability was achieved (Table 2 ). Convergent validity was tested by a computation of Average Variance Extracted (Anderson et al., 2003) for every construct. Since those constructs include items with low factor loadings, the convergent validity of two of the constructs, enjoyment and pride, is close to the desired values, 0.47 and 0.48 , respectively (Table 2). Nevertheless, whenever a construct's AVE is lower than 0.5, though, its composite reliability is higher than 0.6, the construct's convergent validity is still adequate (Fornell \& Larcker, 1981). Associations between self-efficacy and positive emotions and between web camera usage and positive emotions were investigated using multiple regression models. A multiple regression model also tested whether the association of web camera usage with positive emotions is moderated by self-efficacy. The moderation model was performed using the Hayes's Process Macro statistical method (Hayes, 2013). The interaction variable was composed of the product of the mean centers of self-efficacy and web camera usage. Next, the independent variables and the interaction were entered into a simultaneous regression model. 
Table 2. Composite reliability and convergent validity

\begin{tabular}{|c|c|c|c|}
\hline & Items & CR & $\alpha$ \\
\hline 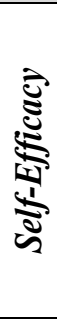 & $\begin{array}{l}\text { I believe I will receive an excellent grade in this class. } \\
\text { I am certain I can understand the most difficult material presented in the readings for this } \\
\text { course. } \\
\text { I am confident I can understand the basic concepts taught in this course. } \\
\text { I am confident I can understand the most complex material presented by the instructor in } \\
\text { this course } \\
\text { I am confident I can do an excellent job on the assignments and tests in this course. } \\
\text { I expect to do well in this class. } \\
\text { I am certain I can master the skills being taught in this class. }\end{array}$ & 0.98 & 0.57 \\
\hline \multirow{3}{*}{ 䢣 } & $\begin{array}{l}\text { Enjoyment } \\
\text { I look forward to studying. } \\
\text { I enjoy the challenge of learning the material. } \\
\text { I enjoy acquiring new knowledge. } \\
\text { I enjoy dealing with the course material. } \\
\text { Reflecting on my progress in coursework makes me happy. } \\
\text { I study more than required because I enjoy it so much. } \\
\text { I am so happy about the progress I made that I am motivated to continue studying. } \\
\text { Certain subjects are so enjoyable that I am motivated to do extra readings about them. } \\
\text { When my studies are going well, it gives me a rush. } \\
\text { I get physically excited when my studies are going well. }\end{array}$ & 0.89 & 0.47 \\
\hline & $\begin{array}{l}\text { Hope } \\
\text { I have an optimistic view toward studying. } \\
\text { I feel confident when studying. } \\
\text { I feel confident that I will be able to master the material. } \\
\text { I feel optimistic that I will make good progress at studying. } \\
\text { The thought of achieving my learning objectives inspires me. } \\
\text { My sense of confidence motivates me. }\end{array}$ & 0.91 & 062 \\
\hline & $\begin{array}{l}\text { Pride } \\
\text { I am proud of myself. } \\
\text { I am proud of my capacity. } \\
\text { I think I can be proud of my accomplishments at studying. } \\
\text { Because I want to be proud of my accomplishments, I am very motivated. } \\
\text { When I solve a difficult problem in my studying, my heart beats with pride. } \\
\text { When I excel at my work, I swell with pride. }\end{array}$ & 0.83 & 0.48 \\
\hline
\end{tabular}

Slope analysis of continuous moderator commonly performed (Table 3) three points of the moderator: the moderator's mean, 1 SD above its mean, and 1 SD below its mean. The moderator's significance regions analysis was performed using the Johnson-Neyman (1936) method.

Table 3. Summary of the simple slopes analysis

\begin{tabular}{|c|c|c|c|c|}
\hline \multicolumn{5}{|c|}{ Simple slopes - Self-Efficacy: mean, +1SD, -1SD } \\
\hline Self-Efficacy & $\mathrm{b}$ & SE & $\mathrm{T}$ & $\mathrm{P}$ \\
\hline High: - +1SD & -.0623 & 0.0661 & -0.9432 & 0.3467 \\
\hline Mean & .0328 & 0.0468 & 0.7014 & 0.4838 \\
\hline Low: -1SD & .1279 & 0.0648 & $1.9755^{*}$ & 0.0495 \\
\hline
\end{tabular}

Statistical significance was set at the $\mathrm{p} \leq .05$ significance level.

\section{Descriptive results}

Mean values, standard deviations, and correlations for students' self-efficacy, positive emotions, and web camera usage are presented in Table 4. 


\section{Issues in Information Systems}

Volume 22, Issue 1, pp. 149-163, 2021

Table 4. Descriptive statistics and Pearson's correlations

\begin{tabular}{|l|l|l|l|}
\hline \multicolumn{1}{|c|}{ Constructs } & \multicolumn{1}{c|}{ Web Camera Usage } & Self-Efficacy & Positive Emotions \\
\hline Web Camera Usage & & & \\
\hline Self-Efficacy & $.232^{* *}$ & & \\
\hline Positive Emotions & $.189^{* *}$ & $.651^{* *}$ & \\
\hline Mean & 3.949 & 5.085 & 11.524 \\
\hline Std Dev & 2.062 & 1.026 & 1.815 \\
\hline Minimum & 1 & 1.14 & 4.2 \\
\hline Maximum & 7 & 7 & 15 \\
\hline
\end{tabular}

Note: $* \mathrm{p}<0.05, * * \mathrm{p}<0.01$.

Overall model: $\mathrm{F}(3,211)=54.47, \mathrm{p}<.001, \mathrm{R}^{2}=43.65 \%$

There was a positive significant correlation between self-efficacy and positive emotions ( $\mathrm{r}(213)=.651$, $\mathrm{p}=.000$ ); thus, higher levels of self-efficacy are associated with higher levels of positive emotions. The other correlations are presented in Table 4.

As shown in Table 5, the multiple regression model results indicated a significant effect for self-efficacy (b $=1.12, \mathrm{t}(211)=11.84, p<.01)$. In contrast, web camera usage was found to be insignificant $(\mathrm{b}=.03$, $\mathrm{t}(211)=.70, p=.48)$. Additionally, the interaction between web camera usage and self-efficacy was also significant $(\mathrm{b}=-.0927, \mathrm{t}(211)=-2.0784, p<.05)$, indicating that the relationship between web camera usage and positive emotions is moderated by self-efficacy.

To elucidate the source of the interaction, simple slopes for the association between web camera usage and positive emotions were tested for low $(-1 \mathrm{SD}$ below the mean $=4.64)$, medium $(5.08)$, and high $(+1 \mathrm{SD}$ above the mean $=5.60$ ) levels of self-efficacy. For unstandardized coefficient $\mathrm{b}$ for low level of self-efficacy, the slope analysis revealed a significant positive association between web camera usage and positive emotions $(\mathrm{b}=.1279, \mathrm{t}(211)=1.9755, p<.05)$. No significant effect was found for either medium $(\mathrm{b}=$ $.0328, \mathrm{t}(211)=.7014, p=.4838)$ or high $(\mathrm{b}=-.0623, \mathrm{t}(211)=-.9432, p=.3467)$ levels of self-efficacy. Figure 2 plots the simple slopes for the interaction.

Table 5. Summary of the multiple regression analysis

\begin{tabular}{|l|l|l|l|l|}
\hline Dependent variable - Positive emotions & SE & T & P \\
\hline Predictors & $\mathrm{b}$ & 0.0961 & 120.4312 & 0.0000 \\
\hline Constant & 11.5695 & 0.0468 & 0.7014 & 0.4838 \\
\hline Web camera usage & .0328 & 0.0943 & $11.8425^{* *}$ & 0.0000 \\
\hline Self-Efficacy & 1.1167 & 0.0446 & $-2.0784^{*}$ & 0.0389 \\
\hline Interaction & -.0927 & & \\
\hline
\end{tabular}


No statistical differences were found for any of the calculations between students in their first year and second year of studies. No statistical differences were found for gender.

\section{Discussion and conclusion}

The COVID-19 pandemic has changed the world, as we knew it. Since its outbreak, millions of employees have left behind their convenient and familiar offices and routines, and now provide their services remotely. Likewise, millions of students were instructed to stay at home and were suddenly confronted with significant and unknown challenges stemming from having to make a rapid transition from frontal learning to

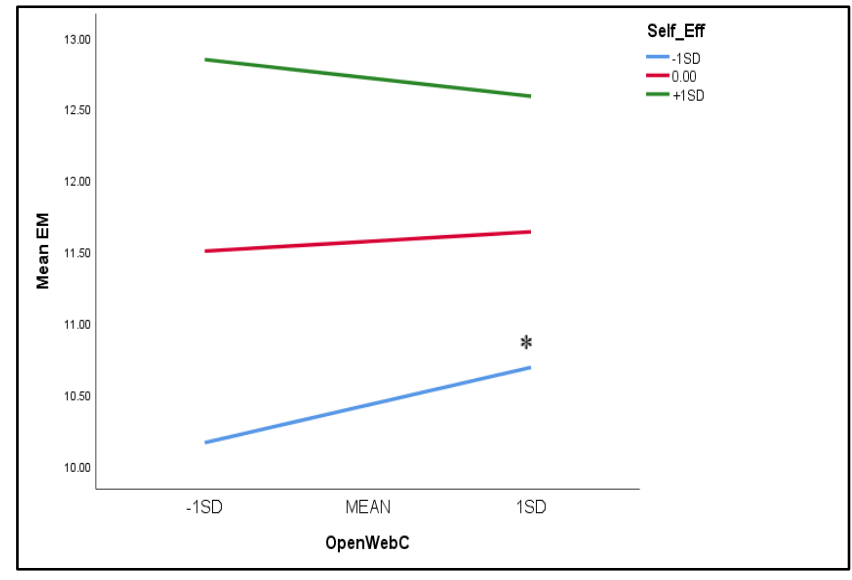

Figure 2. The moderation effect of self-efficacy on the association between camera usage and positive emotions distance learning. Previous research found that learning-related emotions could play a mediating role in the relationship between students' self-efficacy and academic performance (Hayat et al., 2020). However, these relationships were displayed in co-located setting, which is very different from today's online learning setting. Therefore, this newly implemented learning approach requires a close and detailed examination. The research results confirmed that the effect of self-efficacy on positive academic emotions, which was previously found in the co-located setting, also applies to the distance learning setting. The findings show that in the remote learning setting, higher levels of self-efficacy are associated with higher levels of positive academic emotions, thus confirming the first hypothesis. Moreover, the second hypothesis, which predicted the absence of the effect of web camera usage on positive academic emotions, was also supported. These results seem to support the idea that web camera usage is important and beneficial. However, web camera usage may have other advantages in addition to positive academic emotions. Therefore, when teachers insist on students' turning on their web cameras, they should understand that this might not actually affect students' positive academic emotions but may have other beneficial results. Teachers should also be aware that their insistence that students turn on their web cameras might perhaps be more of a reflection of their own preferences, rather than those of their students. Partial support for this argument can be found in prior findings (Castelli \& Sarvary, 2021), focusing on what was not reported as being related to web camera usage. None of the previous arguments associated with web cameras directly depicted students' positive academic emotions. Allegedly, web camera usage does not affect positive academic emotions. Notwithstanding, the results of the current study suggest that students with low self-efficacy benefit from turning on their web cameras, and this effect seemingly does not apply to students with high self-efficacy. Apparently, the effect of self-efficacy on positive academic emotions, for students characterized with substantial self-efficacy, may be projected to the co-located setting, meaning, they are indifferent to richer CMC tools. Therefore, increased web camera usage does not affect their positive academic emotions. On the other hand, students with low self-efficacy are prone to displaying lower levels of positive academic emotions. Hence, their cooperation with teachers' requests may enable teachers to deliver their courses in a way that better meets the needs of the cooperating students. Thus, students who turn on their web cameras display higher levels of enjoyment, higher levels of pride in their achievements, and therefore higher levels of hope, confirming the third hypothesis, as seen in Figure 2.

Adopting the digital natives vs digital immigrants concept (Prensky, 2001), the research results reflect the characteristics of Generation Z (Dangmei \& Singh, 2016), whose members are dubbed as "digital natives", although this title may be less than accurate in terms of education. In other words, despite Generation $Z$ 


\section{Issues in Information Systems}

Volume 22, Issue 1, pp. 149-163, 2021

members' young age and the fact that they are accustomed to today's "screen mentality", throughout their childhood and during their following years at schools, they studied in a co-located setting - first with their kindergarten teachers, and then with their school teachers. Up until the outbreak of COVID-19, these young students had little or no experience with distance learning. Therefore, as regards the digital natives versus immigrant natives question within the education domain, these youngsters are not really "digital natives". For the most part, students are unaware of the consequences of their decision not to use a web camera during lessons, in terms of their lower psychological engagement and the resultant inferior interactive learning (Krystalli, 2020; Neuwirth et al., 2020). Indeed, there is a variety of legitimate constraints which students cope with, that prevent them from turning on their web cameras. Leading information communication technology (Savicki et al., 1996) vendors, aware of these constraints, constantly attempt to offer improved versions with new features that address these constraints. One such example enables users to set a customized virtual background (Henry \& Shellenbarger, 2020), which addresses environmental inhibitors. In addition to virtual backgrounds, vendors also offer various video filters, which enable participants to hold more vivid sessions, increase their involvement, and blur inconvenient visual flaws, by coloring their eyebrows, lips, beards, and more. Nevertheless, the current level of cooperation with the request to turn on web cameras implies that the current solutions may be insufficient and further ICT (Information and Communication Technologies) capabilities are needed in order to gain more cooperation. Previous research found that learning-related emotions could play a mediating role in the relationship between students' self-efficacy and academic performance (Hayat et al., 2020). The current research focused on the first part, and validated the existence of the effect of self-efficacy on positive academic emotions. However, the study did not address the second part, which relates to the effect of positive academic emotions on academic performance. Although intuitively, and based on previous work, this effect is expected to apply to distance learning as well, the new setting encompasses new and unique technological characteristics and constraints, which may impact this effect.

This theoretical model implies the antecedents of positive academic emotions, especially the mediating effect of web camera usage on the association between self-efficacy and positive academic emotions. The research results revealed that students with low self-efficacy levels experienced higher positive academic emotions as a result of turning on their web cameras, and that this phenomenon was not demonstrated in other self-efficacy levels. Additional results validated the previously known effect of self-efficacy on positive academic emotions, which were found in co-located settings, in the distance learning setting. Therefore, one of the most important activities is to spread the word - both to students as well as educators - by sharing the benefits of using a web camera, and encouraging students to take advantage of this medium.

\section{Practical implications}

ICT education focuses on the education of all parties regarding web camera codes of conduct. The core of ICT education pertains to managing other students' comments regarding visuals, and a set of actions that deal with disobedience regarding these guidelines. In addition, IT education that includes soft aspects can easily make a change and enhance the learning experience by, for example, simply changing the default setting of the web camera, upon joining a lesson. Apparently, a default setting that automatically turns the web camera on when the student joins a lesson, may increase overall usage, thus further empowering students.

\section{Limitations}

Although these findings substantiate the research model, there are also clear limitations in the present research. First, the sample consisted of undergraduate Information Systems students from a single institution in a single location in the world, and reflects the perceptions of students from only two courses. 


\section{Issues in Information Systems}

Volume 22, Issue 1, pp. 149-163, 2021

Therefore, it is unclear whether these findings are generalizable, or if they can be applied to other populations. The web-camera usage measurement consists of a single item with a 7-point Likert scale. A more robust construct with additional facets may provide a better understanding of the web camera effect. In addition, the data reflects the results of a specific semester, when all courses were taught entirely via Zoom. Therefore, it is unclear whether these results apply only to this specific tool in fully synchronous and remote courses, or whether these results apply also to more blended course settings. Moreover, one of the two researchers was the students' Head of the Information Systems Program; thus, students' answers may be biased, despite the researchers' pledge of anonymity. Upon the limitations stated above, this paper is more of a case study than a population study. Besides, the results reflect the students' subjective perceptions, rather than the objective results of actual web camera usage supported by students' performance. Furthermore, while the interaction effect was found to be significant, the $p$-value $(0.0389)$ implies that replication of this research may be beneficial. Similarly, despite the acceptance of the convergent validity test performed with AVE, the values of two of the constructs were slightly lower than 0.5 . Again, replication of this research may shed some light on these results.

\section{Future research}

The research results address the idea of "digital natives". Up until the COVID-19 outbreak, these youngsters were used to learning in traditional frontal, face-to-face classes. This raises two questions: Do the research findings also apply to these students' parents, who are "digital immigrants"? Will these results apply to the next generations, which will be born into a more substantial virtual learning environment? In light of the pitfalls and limitations of distant learning further investigation is required regarding the effect of distance learning on performance, and the academic results of this type of learning during the COVID-19 period. Objective data about web camera usage and students' performance may also improve the understanding of the effect of web camera usage in academic activities. Some of the previous research focused on teachers' preferences and the desire to see their students during distance learning lessons; other studies focused on the other part of the equation and investigated the students' realm. Thus, another plausible area of research may be an endeavor to grasp the two sides of the equation, and to offer a comprehensive perspective of appropriate web camera usage, according to the preferences of both parties.

\section{References}

Al-Jarf, R. (2020). Distance learning and undergraduate Saudi students' agency during the Covid-19 Pandemic. Bulletin of the Transilvania University of Brasov, 13, 2020. https://doi.org/10.31926/but.pcs.2020.62.13.2.4

Albuquerque, N., \& Velho, L. (2003). Togetherness through Virtual Worlds: How real can be that Presence?

Anderson, R., Beavers, J., VanDeGrift, T., \& Videon, F. (2003). Videoconferencing and presentation support for synchronous distance learning. 33rd Annual Frontiers in Education, 2003. FIE 2003.

Bandura, A. (1997). Self-efficacy: The exercise of control. W H Freeman/Times Books/ Henry Holt \& Co.

Blas, N. D., \& Poggi, C. (2007). European virtual classrooms: building effective "virtual" educational experiences. Virtual Reality, 11(2), 129-143. https://doi.org/10.1007/s10055-006-0060-4

Burić, I., \& Macuka, I. (2018). Self-Efficacy, Emotions and Work Engagement Among Teachers: A Two Wave Cross-Lagged Analysis. Journal of Happiness Studies, 19(7), 1917-1933. 


\section{Issues in Information Systems}

Volume 22, Issue 1, pp. 149-163, 2021

Burić, I., Slišković, A., \& Sorić, I. (2020). Teachers' Emotions and Self-Efficacy: A Test of Reciprocal Relations. Frontiers in Psychology, 11.

Castelli, F. R., \& Sarvary, M. A. (2021). Why students do not turn on their video cameras during online classes and an equitable and inclusive plan to encourage them to do so. Ecology and Evolution, $n / a(\mathrm{n} / \mathrm{a})$.

Dangmei, J., \& Singh, A. (2016). UNDERSTANDING THE GENERATION Z: THE FUTURE WORKFORCE. 3, 1-5.

Fita, A., Monserrat, J. F., Moltó, G., Mestre-Mestre, E., \& Rodriguez-Burruezo, A. (2016). Use of synchronous e-learning at university degrees. Computer Applications in Engineering Education, 24.

Fornell, C., \& Larcker, D. F. (1981). Evaluating Structural Equation Models with Unobservable Variables and Measurement Error. Journal of Marketing Research, 18(1), 39-50. https://doi.org/10.2307/3151312

Frenzel, A., Goetz, T., Lüdtke, O., Pekrun, R., \& Sutton, R. (2009). Emotional Transmission in the Classroom: Exploring the Relationship Between Teacher and Student Enjoyment. First publ. in: Journal of Educational Psychology, 101 (2009), 3, pp. 705-716, 101. https://doi.org/10.1037/a0014695

Goleman, D. (1995). Emotional intelligence. Bantam Books, Inc.

Govaerts, S., \& Grégoire, J. (2008). Development and Construct Validation of an Academic Emotions Scale. International Journal of Testing, 8(1), 34-54. https://doi.org/10.1080/15305050701808649

Greener, S. (2021). Exploring remote distance learning: what is it and should we keep it? Interactive Learning Environments, 29(1), 1-2. https://doi.org/10.1080/10494820.2021.1848506

Griffiths, M., \& Graham, C. (2009). Using asynchronous video in online classes: Results from a pilot study. International Journal of Instructional Technology and Distance Learning, 6.

Gruber, A., \& Bauer, E. (2020). Fostering Interaction in Synchronous Online Class Sessions with Foreign Language Learners. In (pp. 175-178).

Gunawardena, C. N., \& McIsaac, M. S. (2003). Distance education. In D. H. Jonassen (Ed.), Handbook of research on educational communications and technology (2nd ed., pp. 355-395). Lawrence Erlbaum Associates Publishers.

Hayat, A. A., Shateri, K., Amini, M., \& Shokrpour, N. (2020). Relationships between academic selfefficacy, learning-related emotions, and metacognitive learning strategies with academic performance in medical students: a structural equation model. BMC Medical Education, 20(1), 76. https://doi.org/10.1186/s12909-020-01995-9

Hayes, A. F. (2013). Introduction to mediation, moderation, and conditional process analysis: A regression-based approach. Guilford Press. 


\section{Issues in Information Systems}

Volume 22, Issue 1, pp. 149-163, 2021

Henry, A., \& Shellenbarger, T. (2020). To Zoom or not to Zoom? Choosing a videoconferencing platform. Nurse Author \& Editor, n/a(n/a). https://doi.org/https://doi.org/10.1111/nae2.9

Hoyle, R. H. (1995). Structural equation modeling : concepts, issues, and applications. Sage Publications.

Izard, C. E. (1985). Emotions, cognition, and behavior. Cambridge University Press.

John-Steiner, V. (2000). Creative collaboration. Oxford University Press.

Johnson, P. O., \& Neyman, J. (1936). Tests of certain linear hypotheses and their application to some educational problems. Statistical Research Memoirs, 1, 57-93.

Kline, R. B. (1998). Principles and practice of structural equation modeling. Guilford Press.

Krystalli, P. (2020). Undergraduate Students' Perceptions of Virtual Teaching. European Journal of Social Science Education and Research; Vol 7 No 3 (2020): September - December 2020.

Loehlin, J. C. (1992). Latent variable models : an introduction to factor, path, and structural analysis (2nd ed.). Lawrence Erlbaum Associates.

Lowenthal, P., Borup, J., West, R., \& Archambault, L. (2020). Thinking Beyond Zoom: Using Asynchronous Video to Maintain Connection and Engagement During the COVID-19 Pandemic. Journal of Technology and Teacher Education, 28, 383-391.

McBrien, J., Rui, C., \& Jones, P. (2009). Virtual Spaces: Employing a Synchronous Online Classroom to Facilitate Student Engagement in Online Learning. International Review of Research in Open and Distance Learning, 10. https://doi.org/10.19173/irrodl.v10i3.605

Meeter, M., Bele, T., Hartogh, C., Bakker, T., de Vries, R., \& Plak, S. (2020). College students' motivation and study results after COVID-19 stay-at-home orders. https://doi.org/10.31234/osf.io/kn6v9

Mega, C., Ronconi, L., \& De Beni, R. (2014). What makes a good student? How emotions, self-regulated learning, and motivation contribute to academic achievement. Journal of Educational Psychology, 106(1), 121-131.

Miller, P. W. (1988). Nonverbal Communication. Third Edition. What Research Says to the Teacher [microform] / Patrick W. Miller. Distributed by ERIC Clearinghouse. https://eric.ed.gov/?id=ED293190

Moorhouse, B. L. (2020). Adaptations to a face-to-face initial teacher education course 'forced' online due to the COVID-19 pandemic. Journal of Education for Teaching, 46(4), 609-611.

Mottet, T. P., \& Richmond, V. P. (2002). Student nonverbal communication and its influence on teachers and teaching. In J. L. Chesebro \& J. C. McCroskey (Eds.), Communication for teachers (pp. 4761). Allyn and Bacon. 


\section{Issues in Information Systems}

Volume 22, Issue 1, pp. 149-163, 2021

Neuwirth, L., Jović, S., \& Mukherji-Ratnam, R. (2020). Reimagining higher education during and postCOVID-19: Challenges and opportunities. Journal of Adult and Continuing Education, 147797142094773.

Pekrun, R. (2006). The Control-Value Theory of Achievement Emotions: Assumptions, Corollaries, and Implications for Educational Research and Practice. Educational Psychology Review, 18(4), 315341.

Pekrun, R., Frenzel, A. C., Goetz, T., \& Perry, R. P. (2007). Chapter 2 - The Control-Value Theory of Achievement Emotions: An Integrative Approach to Emotions in Education. In P. A. Schutz \& R. Pekrun (Eds.), Emotion in Education (pp. 13-36). Academic Press.

Pekrun, R., Goetz, T., Frenzel, A., Barchfeld, P., \& Perry, R. (2011). Measuring emotions in students' learning and performance: The Achievement Emotions Questionnaire (AEQ). Contemporary Educational Psychology, 36, 36-48. https://doi.org/10.1016/j.cedpsych.2010.10.002

Pekrun, R., Goetz, T., Titz, W., \& Perry, R. P. (2002). Positive emotions in education. In Beyond coping: Meeting goals, visions, and challenges. (pp. 149-173). Oxford University Press.

Piaget, J. (1989). The relationship between intelligence and affectivity in the development of the child. In B. Rimé \& K. Scherer (Eds.), The Emotions (pp. 75-95). Delachaux and Niestlé.

Pintrich, P., Smith, D., Duncan, T., \& McKeachie, W. (1991). A Manual for the Use of the Motivated Strategies for Learning Questionnaire (MSLQ). Ann Arbor. Michigan, 48109, 1259.

Prensky, M. (2001). Digital Natives, Digital Immigrants Part 2: Do They Really Think Differently? On the Horizon, 9(6), 1-6. https://doi.org/10.1108/10748120110424843

Reich, J., Buttimer, C., Coleman, D., Colwell, R., Faruqi, F., \& Larke, L. (2020). What's Lost, What's Left, What's Next: Lessons Learned from the Lived Experiences of Teachers during the 2020 Novel Coronavirus Pandemic. https://doi.org/10.35542/osf.io/8exp9

Salanova, M., Llorens Gumbau, S., \& Schaufeli, W. (2010). "Yes, I Can, I Feel Good, and I Just Do It!" On Gain Cycles and Spirals of Efficacy Beliefs, Affect, and Engagement. Applied Psychology, $60,255-285$.

Savicki, V., Kelley, M., \& Lingenfelter, D. (1996). Gender and Group Composition in Small Task Groups Using Computer-Mediated Communication. Computers in Human Behavior, 12(2), 209-224.

Schermelleh-Engel, K., Moosbrugger, H., \& Müller, H. (2003). Evaluating the Fit of Structural Equation Models: Tests of Significance and Descriptive Goodness-of-Fit Measures. Methods of Psychological Research, 8(2), 23-74.

Short, J., Williams, E., \& Christie, B. (1976). The social psychology of telecommunications.

Taxer, J., \& Frenzel, A. (2015). Facets of teachers' emotional lives: A quantitative investigation of teachers' genuine, faked, and hidden emotions. Teaching and Teacher Education, 49, 78-88. 


\section{Issues in Information Systems}

Volume 22, Issue 1, pp. 149-163, 2021

Telles, J. (2010). Do we really need a webcam? The uses that foreign language students make out of webcam images during teletandem sessions. Revista Letras \& Letras, 25(2), 65-79.

Vandenberg, R. J. (2006). Introduction: Statistical and Methodological Myths and Urban Legends: Where, Pray Tell, Did They Get This Idea? Organizational Research Methods, 9(2), 194-201.

Vygotsky, L. S., van der Veer, R., \& Valsiner, J. (1994). The problem of the environment. In The Vygotsky reader. Cambridge, MA, US: Basil Blackwell.

Weiner, B. (2010). Attribution Theory. In. https://doi.org/10.1002/9780470479216.corpsy0098

Yamada, M., \& Akahori, K. (2009). Awareness and Performance through Self- and Partner's Image in Videoconferencing. CALICO Journal, 27(1), 1-25.

http://www.jstor.org/stable/calicojournal.27.1.1 